\title{
SATISFACTION WITH ORGANIZATIONAL ASPECTS OF HEALTH CARE PROVISION AMONG LITHUANIAN PHYSICIANS
}

\author{
Jonas Kairys ${ }^{1}$, Egle Žebiene ${ }^{2}$, Virginijus Šapoka ${ }^{2}$, Ignas Zokas ${ }^{3}$ \\ ${ }^{1}$ Department of Social Medicine, Vilnius University, Lithuania \\ ²Department of Internal Medicine, General Practice and Oncology, Vilnius University, Lithuania \\ ${ }^{3}$ Group of Social Analysis, Lithuania
}

\section{SUMMARY}

Background: Physician satisfaction is considered an important factor influencing quality of health care provision, patient compliance, and costs to health care systems. Dissatisfaction leads to an increase in turnover of physicians and early retirement, which has a negative impact on continuity and quality of health care. Physician dissatisfaction with certain aspects of health care provision may also help to identify potential weaknesses in satisfactory functioning of health care systems. The aim of the current research project is to study the satisfaction with different organizational aspects of health care provision in Lithuania as judged by a selection of physicians.

Method: The study was conducted in Lithuania in June 2004. Physicians in randomly selected health care centers were invited to take part in the survey, 505 primary and secondary care physicians were interviewed by external interviewers during the study period. Physicians were asked to express their satisfaction on items presented in a questionnaire. The questionnaire consisted of 22 questions, evaluating different aspects of health care services - working conditions, workload, financial remuneration, organization of health care infrastructure and availability of laboratory services. Answers were presented by the 5 point Likert type scale, ranging from "very satisfied" (5) to "very dissatisfied" (1).

Results: Physicians who were most satisfied with their working conditions were working in private primary health care practices (91.1\% satisfied or very satisfied), as compared with $54 \%$ of physicians working in state-owned primary care institutions and $49.7 \%$ in hospitals. Physicians working in cities and regional centers or towns were more satisfied with organizational aspects of health care services than physicians working in rural health care centers. Satisfaction with their financial remuneration showed that $74 \%$ of respondents stated they were "dissatisfied" or "very dissatisfied". While asked about potential deficiencies in their health care institutions, the most important identified by respondents in all localities was a perceived lack of financial support for these institutions.

Conclusions: There is a significant difference in the perception of physicians in private and state health care institutions with regard to financial remuneration as well as availability of laboratory diagnostic and treatment equipment and working conditions. Based on the study findings, possibilities to increase Primary Care financing should be considered in order to improve the quality of the delivery of health care services as well as retain physicians within the health care system. Results of this study demonstrate a need of further research to quantify what could be reasonably expected from diagnostic and investigative resources to support health care in Lithuania in current economic situation.

Key words: physician satisfaction, health care quality, health care delivery, job satisfaction

Address for correspondence: J. Kairys, Seskines Outpatient Clinic, Seskines st. 24, LT-07156, Vilnius, Lithuania. E-mail: kajo@ktl.mii.It.

\section{INTRODUCTION}

The Lithuanian health care system has gone through rapid change during the last decade. A move from the previously integrated health care model towards the contractual model was prompted by two major factors: the appearance of third party funding in the form of a statutory health insurance system, as well as enforcement of legislation redefining property rights and the status of health care institutions (1). Since 1997 patients have had the right to free choice of a primary health care institution and a primary care physician. Financial remuneration of health care providers now depends on the number of patients they serve. Determinants of quality as evaluated both by the opinion of patients and medical staff becomes highly important for health care organizers, policy makers and researchers, consequently stimulating demand in research studies (2-6). It is widely acknowledged that measures of processes show how providers can improve activities (7).

Assessment of the patients' opinion about the services is becoming a common process in evaluating the quality of certain dimensions of health care services, attracting the attention of Lithuanian researchers during the last decade $(3,5,6)$. Physician satisfaction is another fundamental factor influencing the quality of the health care provision. There is an association between physician satisfaction, quality of care they provide, and patient satisfaction (8-9). Physicians are considered to be more effec- 
tive in their work when they are professionally satisfied, and more attentive to their patients (10). According to some research studies, the professional dissatisfaction may influence the future supply of physicians (11-12). Therefore, physician satisfaction becomes an important issue for policy makers and health care system administrators. Until now this subject has received much less attention from researchers in Lithuania than in other countries $(4,8,13)$.

The aim of the current research project is to study the satisfaction with different organizational aspects of health care provision in Lithuania as judged by a selection of physicians. Further comparison of views of patients and physicians, as well as similar studies performed in other countries, could help in the development of strategies for improvement of health care services delivery.

\section{SUBJECTS AND METHODS}

\section{Subjects}

The study has been conducted in Lithuania in June 2004. Physicians in randomly selected health care institutions were asked to participate in the study. Institutions were selected using stratified probability sampling based on the database of the State Patient Fund. In order to have a distribution which reflected the current situation in the Lithuanian health care system, selection was made according to locality (cities, regional towns, and countryside), type of health care institution (primary health care centers, hospitals) and type of practice (private or state-owned). 596 physicians were included in the targeted study sample. Participants were interviewed personally by external interviewers.

\section{Questionnaire}

The questionnaire was developed by the study team on the basis of results of previous research studies performed both internationally and in Lithuania $(1,9,10)$. A pilot study in order to test the instrument was performed on a representative sample of the population; no essential changes were required to be made to the questionnaire and research methodology. The questionnaire consisted of 22 questions, evaluating different aspects of health care services - working conditions, workload, financial remuneration, organization of health care services, availability of laboratory tests, possible shortcomings and some other determinants. Answers were presented by the 5 point Likert type scale from "very satisfied" (5) to "very dissatisfied" (1). Other items included into the questionnaire were personal characteristics of respondents.

\section{Statistical analysis}

SPSS software was used for statistical analysis of the data. The correlation between the respondents' satisfaction and quality indicators presented in questionnaire was analyzed by $\chi^{2}$ test. Differences between groups were considered statistically significant when $p<0.050$. There were no statistically significant differences in the age range of respondents in different practice localities or practice types; therefore the age standardization of results was not performed. Spearman correlation (Rs) was used to investigate possible dependency of variables.

\section{RESULTS}

596 physicians were invited to answer the questionnaires, 505 agreed to take part in the study, making up response rate 84.7. 143 (28.3\%) of respondents were male, 362 (71.7\%) were female. The mean age of respondents was 49.1 years [standard deviation (SD) was 8.86].

272 (53.9\%) of respondents were working in state-owned primary care centers. 177 (35.0\%) were working in hospitals, 56 (11.1\%) of respondents were working in private primary care practices. 263 respondents (52.1\%) of study participants were general practitioners or primary care internists, 242 (47.9\%) were secondary care specialists.

Distribution of respondents in regard to their length of time in practice was as follows: less than 5 years in practice -54 (10.7\%) of respondents, $6-15$ years: 118 (23.4\%) of respondents, 16 years or more: 333 (65.9\%) study respondents.

Analysis of the satisfaction with working conditions showed that $56.7 \%$ of physicians were "satisfied" or "very satisfied". Respondents working in cities and regional towns scored more highly for "satisfaction" (55.6\% and 60.5\%, respectively) than physicians working in rural area (51.6\%). Although their answers suggest they are less satisfied than those in towns and cities, the percentage of them reporting satisfaction was still higher than of those in rural areas that were dissatisfied (24.8\%).

The percentage of male doctors who expressed that they were "satisfied" or "very satisfied" was higher than that of female doctors (59.5\% and 55.6\%, respectively).

$\chi^{2}$ test has proved these differences to be statistically significant $(p<0.050)$.

The results of the questionnaire satisfaction of participants asking about working conditions, with details of the type of the institution of the respondent are presented in Fig. 1. Those most satisfied with their working conditions are physicians working in private primary health care practices. Less satisfied were physicians in state-owned primary care institutions and hospitals, differences were statistically significant. Evaluation of the results asking about organizational aspects of health care services revealed that $62 \%$ of physicians were "very satisfied" or "satisfied". Those working in cities (65.5\%) and regional centers/towns (62.2\%) were more satisfied than physicians working in rural health care centers (53.6\%) ( $p=0.045)$.

Financial remuneration was most frequently identified problem by study participants: $74 \%$ of respondents stated that they are "dissatisfied" or "very dissatisfied" (Table 1). This response can be broken down as being given by $75.8 \%$ of respondents in cities, $70.8 \%$ working in regional towns, $76.3 \%$ working in rural practices.

The availability of essential clinical tests and investigations was rated as "satisfied" or "very satisfied" by $47.9 \%$ of respondents in cities, $48.7 \%$ of respondents in regional centers/towns, and only $7.2 \%$ of physicians working in rural practices (Table 1 ).

The respondents were asked for their opinion about their workload looking at the number of clinical consultations per day (Table 2). The majority of respondents reported that this number was "very high" or "too high" (26.9\% and 29.5\%, respectively). The current number of consultations thought to be optimal was reported by $37.2 \%$ of all physicians. Evaluation of the number of clinical consultations per day according to the type of institution 
Table 1. Distribution of respondents with their financial remuneration and availability of tests according to the practice type (in percents) $(n=505)$

\begin{tabular}{|c|c|c|c|c|c|c|c|c|c|c|c|c|}
\hline \multirow{3}{*}{ Satisfaction with: } & \multicolumn{4}{|c|}{ State-owned $\mathrm{PHC}^{1}$ centers } & \multicolumn{4}{|c|}{ Hospital } & \multicolumn{4}{|c|}{ Private practice } \\
\hline & \multicolumn{2}{|c|}{$\begin{array}{c}\text { Financial } \\
\text { Remuneration }^{* * *}\end{array}$} & \multicolumn{2}{|c|}{$\begin{array}{l}\text { Availability of } \\
\text { clinical } \\
\text { tests }^{*+1}\end{array}$} & \multicolumn{2}{|c|}{$\begin{array}{c}\text { Financial } \\
\text { remuneration }\end{array}$} & \multicolumn{2}{|c|}{$\begin{array}{c}\text { Availability } \\
\text { of clinical tests }\end{array}$} & \multicolumn{2}{|c|}{$\begin{array}{l}\text { Financial } \\
\text { remuneration }\end{array}$} & \multicolumn{2}{|c|}{$\begin{array}{l}\text { Availability } \\
\text { of clinical tests }\end{array}$} \\
\hline & $\%$ & $\mathrm{n}$ & $\%$ & $\mathrm{n}$ & $\%$ & $\mathrm{n}$ & $\%$ & $\mathrm{n}$ & $\%$ & $\mathrm{n}$ & $\%$ & $\mathrm{n}$ \\
\hline Very satisfied & 0.0 & 0 & 4.8 & 24 & 0.6 & 3 & 17.5 & 88 & 16.1 & 81 & 30.4 & 153 \\
\hline Satisfied & 9.9 & 50 & 21.0 & 106 & 8.5 & 43 & 32.2 & 163 & 57.1 & 288 & 51.8 & 262 \\
\hline Uncertain & 7.4 & 37 & 23.9 & 121 & 9.6 & 48 & 14.1 & 71 & 17.9 & 91 & 8.9 & 45 \\
\hline Dissatisfied & 31.3 & 158 & 35.2 & 178 & 27.1 & 137 & 31.1 & 157 & 7.1 & 36 & 7.1 & 36 \\
\hline Very dissatisfied & 51.4 & 260 & 15.1 & 76 & 54.2 & 274 & 5.1 & 26 & 1.8 & 9 & 1.8 & 9 \\
\hline Total & 100 & 505 & 100 & 505 & 100 & 505 & 100 & 505 & 100 & 505 & 100 & 505 \\
\hline
\end{tabular}

${ }^{*}$ Rs $=-0,162 ; p=0,044$

${ }^{* \star} \mathrm{Rs}=-0,237 ; p=0,042$

${ }^{* \star *} \mathrm{Rs}=-0,280 ; p=0,046$

${ }^{* * * *} \mathrm{Rs}=-0,358 ; p=0,039$

$\mathrm{PHC}^{1}=$ Primary Health Care

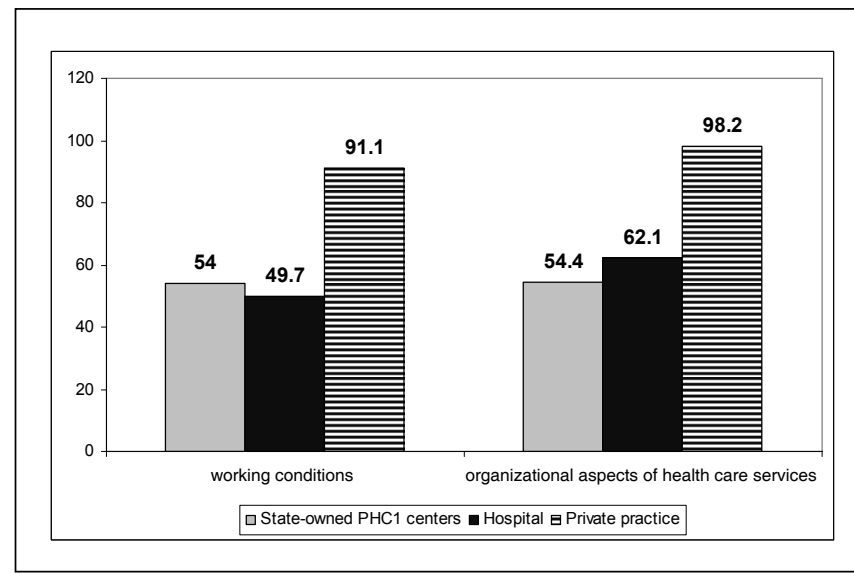

$\mathrm{p}<0.05$

Fig. 1. Satisfaction of physicians with their working conditions and organisation of services according to the practice type (in percents). showed that those most dissatisfied with their workload were physicians working in state-owned PHC institutions ( $p=0.044)$. The majority of physicians working in private practices considered their current number of consultations per day as optimal.

When asked to express their opinion on possible deficiencies in their health care practices, the highest rate, in all localities was a perceived lack of financial resources of the institutions concerned (mean 17.6\%) ( $p=0.045)$. A lack of diagnostic, laboratory or treatment equipment was identified by the respondents as the second highest deficiency (Table 3).

\section{DISCUSSION}

The results of our study clearly demonstrated differences in the opinions of physicians on some quality indicators of health care services, as well as identified potential deficiencies in health care delivery.

Table 2. Distribution of respondents (in percents) according to their opinion on the number of consultations per day, by the type of institution $(n=505)$

\begin{tabular}{|c|c|c|c|c|c|c|c|c|}
\hline \multirow{3}{*}{$\begin{array}{l}\text { Evaluation of the number } \\
\text { of clinical consultations per day }\end{array}$} & \multicolumn{6}{|c|}{ Type of institution } & & \\
\hline & \multicolumn{2}{|c|}{$\begin{array}{l}\text { State-owned } \\
\text { PHC* centers }^{*}\end{array}$} & \multicolumn{2}{|c|}{ Hospital } & \multicolumn{2}{|c|}{ Private practice } & \multicolumn{2}{|c|}{ Mean } \\
\hline & $\%$ & $\mathrm{n}$ & $\%$ & $\mathrm{n}$ & $\%$ & $\mathrm{n}$ & $\%$ & $\mathrm{n}$ \\
\hline Number of consultations is very high & 28.9 & 146 & 29.3 & 148 & 14.3 & 72 & 27.4 & 138 \\
\hline Number of consultations is too high & 34.6 & 175 & 27.6 & 139 & 16.1 & 81 & 30.0 & 152 \\
\hline Number of patients is optimal & 33.1 & 167 & 37.9 & 192 & 60.7 & 307 & 37.9 & 191 \\
\hline Number of consultations is too low & 3.4 & 17 & 5.2 & 26 & 8.9 & 45 & 4.7 & 24 \\
\hline Number of consultations is very low & 0.0 & 0 & 0.0 & 0 & 0.0 & 0 & 0.0 & 0 \\
\hline Total & 100 & 505 & 100 & 505 & 100 & 505 & 100 & 505 \\
\hline
\end{tabular}

*Primary Health Care

$\mathrm{Rs}=0.129 ; p=0.044$ 
Table 3. Distribution of respondents according to their opinion about deficiencies in their institution $(n=505)$

\begin{tabular}{|c|c|c|c|c|c|c|c|c|}
\hline \multirow{3}{*}{$\begin{array}{l}\text { Opinion about deficiencies } \\
\text { in respondents institution }\end{array}$} & \multicolumn{6}{|c|}{ Type of institution } & \multirow{2}{*}{\multicolumn{2}{|c|}{ Mean }} \\
\hline & \multicolumn{2}{|c|}{$\begin{array}{l}\text { State-owned PHC* } \\
\text { centers }\end{array}$} & \multicolumn{2}{|c|}{ Hospital } & \multicolumn{2}{|c|}{ Private practice } & & \\
\hline & $\%$ & $\mathrm{n}$ & $\%$ & $\mathrm{n}$ & $\%$ & $\mathrm{n}$ & $\%$ & $\mathrm{n}$ \\
\hline Financial resources & 18.0 & 91 & 18.3 & 92 & 13.4 & 68 & 17.6 & 89 \\
\hline Diagnostic and treatment equipment & 15.4 & 78 & 13.5 & 68 & 11.1 & 56 & 14.3 & 72 \\
\hline Pharmaceuticals and other medical supplies & 9.4 & 47 & 18.9 & 95 & 0.0 & 0 & 11.8 & 60 \\
\hline Computerization of physician's work & 5.1 & 26 & 2.8 & 14 & 0.0 & 0 & 3.7 & 19 \\
\hline No deficiencies & 4.7 & 24 & 4.8 & 24 & 24.5 & 124 & 6.8 & 34 \\
\hline Efficient management & 1.8 & 9 & 0.7 & 4 & 11.1 & 56 & 2.4 & 12 \\
\hline Building renovation and maintenance & 4.4 & 22 & 2.8 & 14 & 0.0 & 0 & 3.3 & 17 \\
\hline Others & 41.3 & 208 & 38.3 & 194 & 39.9 & 201 & 40.0 & 202 \\
\hline Total & 100 & 505 & 100 & 505 & 100 & 505 & 100 & 505 \\
\hline
\end{tabular}

"Primary Health Care

Rs $=-0.087 ; p=0.045$

According to the study results, physicians working in private health care centers appear to be considerably more satisfied with their working conditions compared with those working in stateowned health care institutions. This finding may be influenced by several factors: small private primary care practices have started to be established in Lithuania since 1998, therefore they are relatively new institutions, built, renovated and equipped according to current standards and may provide better working conditions for their staff. This result is supported by findings of other research studies, reporting that physicians in private practices are more satisfied with their overall practice and office resources (14).

Managerial aspects of health care services appear to be thought more "satisfactory" in towns and cities compared with rural practices. This may be partly explained by the fact that most health care institutions in cities and towns have higher numbers of patients and medical staff, which allows the available financial and human resources to be used more effectively and efficiently. This finding is opposite to conclusions of other studies, which suggest that physicians are less satisfied when working in larger organizations than in smaller practice settings (14).

Financial remuneration and workload were among determinants causing the highest dissatisfaction of physicians in Lithuania as demonstrated by other studies (6). Results of our study revealed that more than two thirds of physicians are dissatisfied with their salaries. Although the level of dissatisfaction varies according to the location and type of the practice, it still remains the factor causing the highest dissatisfaction in this study. As a consequence of falling prestige of the specialty (4), together with financial remuneration which is thought to be "unsatisfactory", a shortage of physicians in the country may be expected in the near future, as more and more young and middle-aged physicians are leaving Lithuania to start working abroad, or have a strong intention to do that (15). The dissatisfaction with financial remuneration may also lead to a physician's attempts to increase patient numbers, reduce support services, restricting the scope of practice, avoid "highrisk” patients and engaging in "defensive” medicine (10).

Workload of physicians is also seen as one of the significant problems in primary health care. The differences of workload between physicians working in private and state-owned Health care institutions may be supported by the data of the State Patient Fund (16), indicating that the mean number of consultations of a private contractor per day is 14.6 , while for a physician working in the state-owned PHC institution it is 19.7. Therefore we argue that differences in physician satisfaction with their workload could be supported by other statistical data of the Lithuanian health care system.

Potential deficiencies of the provision of health care services, according to opinion of respondents, include a shortage of funds for health care institutions, diagnostic and treatment equipment and a lack of computerization of a physician's work. These findings are consistent with the other Lithuanian study, where financial remuneration, social status and workload turned out to be causing the highest dissatisfaction among the respondents (4). The lack of adequate equipment was also pointed out by the qualitative study investigating the opinion of Lithuanian patients about health care services (5).

This study has some limitations. Although it is considered that physician satisfaction with health care services is an important “internal” indicator of well-being of a health care system, it still reflects personal perceptions of physicians rather than objective data. This may suggest careful interpretation is needed of some of our findings. On the other hand, physicians' perceptions of the services may influence their further behavior and their attitude towards patients, and even their own specialty. Physician satisfaction therefore remains an important consideration for the future of the profession. On the other hand, physician satisfaction also may be biased itself by the personal characteristics of respondents, such as age, time in practice, specialty, financial status and some 
others. As our aim was to try to analyze institutional aspects of the health care delivery process, we did not include the analysis of the influence of the personal characteristics of physicians on their satisfaction, in order to focus on organizational issues.

Several practical implications may be suggested, based on our study findings. More adequate financing of health care institutions, resulting both in increased salaries of physicians and improvement of diagnostic and treatment equipment would improve satisfaction of physicians with organization of health care services. Computerization of health care system would also have positive influence on the quality of health care services as perceived by physicians.

\section{CONCLUSIONS}

There is a significant difference in the perception of physicians in private and state health care institutions with regard to financial remuneration as well as availability of laboratory diagnostic and treatment equipment and working conditions. Based on the study findings, possibilities to increase Primary Care financing should be considered in order to improve the quality of the delivery of health care services as well as retain physicians within the health care system.

Results of this study demonstrate a need of further research to quantify what could be reasonably expected from diagnostic and investigative resources to support health care in Lithuania in current economic situation.

\section{Acknowledgments}

The study has been supported by the grant of Ministry of Health Republic of Lithuania.

\section{REFERENCES}

1. Health care systems in transition: Lithuania. Copenhagen: European Observatory on Health Care Systems; 2000.

2. Žebiene E. Patient's expectations and satisfaction with primary health care. Medicina. 2000;36:113-8. (In Lithuanian.)

3. Kairys J, Žebiene E, Gurevicius R, Zokas I. Patients’ viewpoint of in-patient health care services in Lithuania. Visuomenes sveikata. 2003;2(21):45-52. (In Lithuanian.)

4. Buciuniene I, Blazeviciene A, Bliudziute E. Health care reform and job satisfaction of primary health physicians in Lithuania. BMC Fam Pract. 2005 Mar 7;6(1):10-5.

5. Bankauskaite V, Saarelma O. Why are people dissatisfied with medical care services in Lithuania? A qualitative study using responses to openended questions. Int J Qual Health Care. 2003 Feb;15(1):23-9.

6. Zebiene E, Razgauskas E, Basys V, Baubiniene A, Gurevicius R, Padaiga $Z$, et al. Meeting patient's expectations in primary care consultations in Lithuania. Int J Qual Health Care. 2004 Feb;16(1):83-9.

7. Eldar R. Quality of primary care. Croat Med J. 2004 Oct;45(5):679-84.

8. Murray A, Montgomery JE, Chang H, Rogers WH, Inui T, Safran DG. Doctor discontent. A comparison of physician satisfaction in different delivery system settings, 1986 and 1997. J Gen Intern Med. 2001 Jul;16(7):452-9.

9. Haas JS, Cook EF, Puopolo AL, Burstin HR, Cleary PD, Brennan TA. Is the professional satisfaction of general internists associated with patient satisfaction? J Gen Intern Med. 2000 Feb;15(2):122-8.

10. Mello MM, Studdert DM, DesRoches CM, Peugh J, Zapert K, Brennan TA, et al. Caring for patients in a malpractice crisis: physician satisfaction and quality of care. Health Aff (Millwood). 2004 Jun-Aug;23(4):4253.

11. Lichtenstein RL. The job satisfaction and retention of physicians in organized settings: a literature review. Med Care Rev. 1984;41(3):139-79.

12. Mick SS, Sussman S, Anderson-Selling L, DelNero C, Glazer R, Hirsch E, et al. Physician turnover in eight New England prepaid group practices: an analysis. Med Care. 1983 Mar;21(3):323-37.

13. Kairys J, Žebiene E, Zokas I. Nurses viewpoint of health care services in Lithuania. Sveikatos mokslai. 2005;(3):57-62. (In Lithuanian.)

14. Barr DA. The effects of organizational structure on primary care outcomes under managed care. Ann Intern Med. 1995 Mar 1;122(5):353-9.

15. Lovkyte L, Reamy J, Padaiga Z. Physicians resources in Lithuania: change comes slowly. Croat Med J. 2003 Apr;44(2):207-13.

16. The Ministry of Health [homepage on the Internet]. Padaiga Ž. State Patient Fund: overview of year 2004 [cited 2007 Aug 20]. Available from: http://www.vlk.lt/vlk/pag/files/050530_04apzvalga.doc. (In Lithuanian.) 